LA-UR-96- 3224

Title:

Chelating Water-Soluble Polymers for Waste Minimization

Author(s):

Submitted to:
Barbara Smith, CST-12

Michael Cournoyer, CST-12

Brandy Duran, CST-18

Doris Ford, NMT-6

Rowena Gibson, CST-12

Mavis Lin, CST-12

Anne Meck, N,P Energy, Inc.

Patricia Robinson, N,P Energy, Inc.

Thomas Robison, CST-12

DOE Office of Scientific and Technical Information (OSTI)

\section{AECEIVED \\ NOV 141996

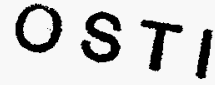

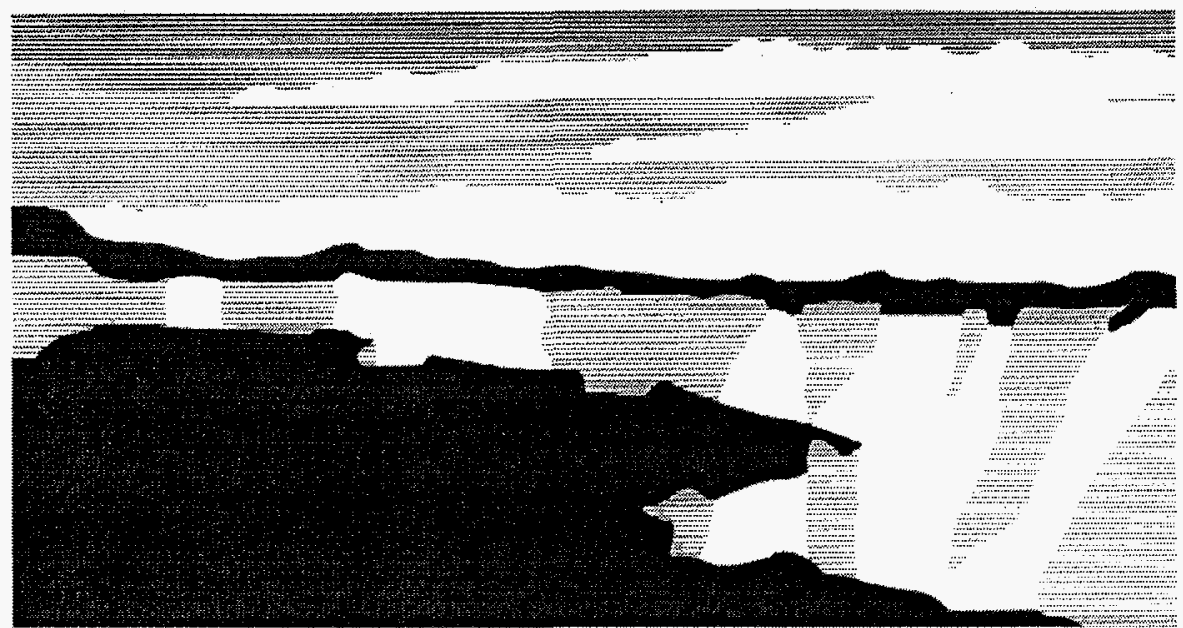

Los Alamos National Laboratory, an atfirmative action/equal opportunity employer, is operated by the University of California for the U.S. Department of Energy under contract W-7405-ENG-36. By acceptance of this article, the publisher recognizes that the U.S. Government retains a nonexclusive, royaltyfree license to publish or reproduce the published form of this contribution, or to allow others to do so, for U.S. Government purposes. The Los Alamos National Laboratory requests that the publisher identify this article as work performed under the auspices of the U.S. Department of Energy. 


\title{
Chelating Water-Soluble Polymers for Waste Minimization
}

\author{
Barbara Smith*, Michael Cournoyer, Brandy Duran, Doris Ford, Rowena \\ Gibson, Mavis Lin, Anne Meck (N,P Energy, Inc.), Patricia Robinson (N,P \\ Energy, Inc.), and Thomas Robison
}

\begin{abstract}
This is the final report of a one-year, Laboratory-Directed Research and Development (LDRD) project at the Los Alamos National Laboratory (LANL). Within the DOE complex and in industry there is a tremendous need for advanced metal ion recovery and waste minimization techniques. This project sought to employ capabilities for ligand-design and separations chemistry in which one can develop and evaluate water-soluble chelating polymers for recovery of actinide and toxic metals from a variety of process streams. The focus of this work was: (1) to develop and select a set of water-soluble polymers suitable for a selected waste stream and (2) demonstrate this technology in two areas: the removal of (a) actinides and toxic RCRA metals from waste water and (b) recovery of copper (and other precious metals) from industrial process streams including from solid catalysts and aqueous waste streams. For this project the research and development was done in four phases for each of the two target areas: (1) polymer synthesis for scale-up, (2) assembly of equipment, (3) process demonstration at a DOE or industrial site, and (4) advanced ligand/polymer synthesis. The TA-50 site at Los Alamos was thought to be appropriate due to logistics and to its being representative of similar problems throughout the DOE complex.
\end{abstract}

\section{Background and Research Objectives}

Within the DOE complex and in industry there is a tremendous need for advanced metal ion recovery and waste minimization techniques. "Separation and Purification: Critical Needs and Opportunities," is a report authored by a committee of the National Research Council, chaired by C. Judson King, professor of chemical engineering at UC Berkeley. This report

\footnotetext{
* Principal investigator, e-mail: bfsmith@lanl.gov
} 


\section{DISCLAIMER}

Portions of this document may be illegible in electronic image products. Images are produced from the best available original document. 


\section{DISCLAIMER}

This report was prepared as an account of work sponsored by an agency of the United States Government. Neither the United States Government nor any agency thereof, nor any of their employees, makes any warranty, express or implied, or assumes any legal liability or responsibility for the accuracy, completeness, or usefulness of any information, apparatus, product, or process disclosed, or represents that its use would not infringe privately owned rights. Reference herein to any specific commercial product, process, or service by trade name, trademark, manufacturer, or otherwise does not necessarily constitute or imply its endorsement, recommendation, or favoring by the United States Government or any agency thereof. The views and opinions of authors expressed herein do not necessarily state or reflect those of the United States Government or any agency thereof. 
gives an approach to separation science and technology that focuses on generic research frontiers. King notes in a preface to the report that the committee has recast the fundamental problems facing separations researchers. The highest-priority research needs and opportunities, where focused efforts could lead to much clearer insights into fundamental principles and major opportunities for technology innovation, were: (1) generating improved selectivity among solutes in separations, and (2) concentrating solutes from dilute solutions. While this need is widely recognized, there are few advanced technologies for metal ion recovery and recycle, which are at or near the demonstration phase.

Here at Los Alamos, there is an integrated program in ligand-design and separations chemistry that has developed and evaluated a series of water-soluble chelating polymers for recovery of actinide and toxic metals from a variety of process streams. We have developed and demonstrated a metal recover technology for application to the electroplating industry where metal ions are being recovered and recycled from electroplating rinse waters. Polymer filtration $(\mathrm{PF})$ uses water-soluble chelating polymers in combination with ultrafiltration for the selective recovery and concentration of metal ions in aqueous solutions. Separation is based on size-exclusion where the polymer-metal complex is physically too large to pass through the ultrafiltration membrane (retentate), while unbound species readily pass through the membrane (permeate). In this way, the polymer-metal complex can be concentrated by simple ultrafiltration. Once concentrated, the metal ions can be selectively released from the polymer by, for example, $\mathrm{pH}$ adjustment and collected in a concentrated form. The metal-free polymer is readily recycled for additional metal-ion binding.

Polymer filtration has several advantages over more conventional metal-ion separation technologies; (1) the homogeneity of the process results in rapid binding and stripping kinetics not ordinarily found in ion-exchange, (2) the water-soluble polymers have high metal-ion capacities, 3-8 times greater than ion exchange, and (3) the polymers used are generally selective for di- and trivalent transition metals, therefore, the presence of high concentration of alkali and alkaline earth metal ions do not interfere. In April 1994, we successfully demonstrated PF on electroplating rinse waters for the recovery and concentration of nickel and zinc ions at Boeing Aerospace, Seattle, Washington, using a pilot-scale unit (2-5 gallons/minute). 


\section{Importance to LANL's Science and Technology Base and National R\&D Needs}

It supports the LANL core competency in Earth and Environmental Systems. This project builds on the successes of polymer filtration technology for a variety of solids, waters, and waste water types for quality production, waste minimization, pollution prevention, and resource recovery. It addresses a pressing national need for advanced metal ion recovery and waste minimization techniques and enhances the Laboratory's visibility and ability to respond to initiatives in these areas.

\section{Scientific Approach and Results to Date}

\subsection{Acid Mine Drainage}

Background: Water flows into the Berkeley Pit from runoff and underground water sources at 3,500 gallons per minute. Acidic water produced from bacterial action on the sulfide ores leaches toxic levels of metal ions from the surrounding mining district in the form of sulfates causing the water to have an acidic $\mathrm{pH}$ of about 2.6. It is anticipated that the pit will overflow by the year 2019. Treatment is required to prevent water from entering the local rivers and aquifers. It is our understanding that the current baseline technology for treatment of the Berkeley Pit Waters (BPW) is precipitation of all metals such that the liquid discharge meets criteria for discharge into a publicly owned treatment works (POTW) or into the local rivers; and that the sludge resulting from the precipitation will be buried back in the original mine tailings or accumulate on the pit bottom. In this way no metal value is recovered and only the overflow issue would be addressed. Precipitation does not address the issue of excess sulfate in the waters. Lime precipitation also does not assure that in the future that fresh acid leach water will not redissolve the metals from the hydroxide precipitate.

Approach: Our primary approach to metal-ion recovery from the Berkeley Pit Water (BPW) samples used polymer filtration (PF) Technology. Our strategy for solving the BPW problem is based on the fact that there are large amounts of nuisance metals present that need to be separated from the valuable and hazardous metals. Non-hazardous metals such as calcium, magnesium, potassium, sodium, can be discharged with the water. It is uncertain if aluminum and iron have any value at this time, but it might be desirable to remove them separately. The main metals of value in large amounts are copper and zinc. Only small amount of nickel are present. The remaining metals are in very small amounts, but must be removed from the water stream before discharge. 
To increase the efficiency of the PF process we felt it would be advantageous to initially remove as much of the iron and aluminum from the water as possible. If left in the waters, their high concentrations would potentially occupy significant portions of the polymers' metalbinding capacity, necessitating greater polymer usage. In addition, for optimum metal-ion binding of the polymers used in our experiments it is necessary that the $\mathrm{pH}$ be raised to approach neutral values (ultimately for discharge to POTW the waters must be near neutral). Additionally, if any electrochemical approaches are used, iron is a major interference because it is quite electroreactive.

We decided to take advantage of the water-soluble polymer's chelating ability in addition to its basicity to eliminate the disadvantages of hydroxide precipitation (slow kinetics). By adding sufficient polymer to complex all the metal ions except iron and aluminum, we anticipated that we could keep the copper, zinc, and other metals in solution bound as polymermetal complexes, while raising the $\mathrm{pH}$ enough to selectively precipitate the iron and aluminum (solubility at $\mathrm{pH} 4.8 \mathrm{Al}(\mathrm{III})=0.1 \mathrm{ppm}, \mathrm{Fe}(\mathrm{III})=0.001 \mathrm{ppm}$ ) .

Experimental: A general procedure involved treating BPW with a dilute solution of Metal-Set-Z polymer to adjust the $\mathrm{pH}$ of the water to near 4.8. The solid precipitate was separated by centrifugation. The $\mathrm{pH}$ of the supernatant was adjusted to higher $\mathrm{pH}$ values to fully bind all the metal ions and then ultrafiltered to concentrate the metal ions and to give the permeate free of hazardous metals for discharge (after sulfate and manganese removal).

The first test involved treating BPW $(20 \mathrm{~mL})$ with dilute polymer solution $(2 \mathrm{~mL}, 50,000$ ppm polymer) to adjust the $\mathrm{pH}$ of the water to $\mathrm{pH} 4.8$. It was noted that upon the addition of the polymer solution, the $\mathrm{pH}$ of the water was raised and immediately stabilized at 4.9 resulting in iron and aluminum precipitation. The supernatant (solution above the solid precipitate) was separated from the solid by centrifugation and allowed to sit overnight. No additional precipitate was observed and the $\mathrm{pH}$ had not changed by more than 0.1 units. This is evidence of the rapid kinetics in the precipitation process. The procedure was repeated a number of times with very reproducible results. Table 1 below gives typical metal-ion concentrations found in the supernatant in comparison to the metal concentrations found in $20 \mathrm{~mL}$ of the Berkeley Pit water. The analysis indicated all the iron and $95 \%$ of the aluminum was removed from solution with zinc (100\%), magnesium (100\%), manganese ((98\%), and copper (72\%) all remaining in solution. A water wash of the precipitate yielded another $10 \%$ of copper bringing the recovery to $82 \%$. It is thought that a continuous wash step would recover more of the polymer-copper complex from the iron/aluminum sludge. The above experiment was repeated on $80 \mathrm{~mL}$ of Berkeley Pit water using $10 \mathrm{~mL}$ of polymer-solution with similar results. This indicates the process can be directly scaleable. 
Table 1. Polymer Treatment of Berkeley Pit Water for Selective Precipitationa

$\begin{array}{cccc}\text { Metal } & \begin{array}{c}\text { Solution } \\ \text { pH } 4.8\end{array} & \begin{array}{c}\text { Permeate } \\ \text { pH } 5.6\end{array} & \begin{array}{c}\text { Berkeley Pit } \\ \text { pH } 2.6\end{array} \\ \mathrm{Cu} & 2.68(72 \%) \mathrm{d} & <0.1^{\mathrm{d}} & \\ \mathrm{Zn} & 11.2(104 \%) & <0.1 & 3.74 \\ \mathrm{Al} & 0.31(5 \%) & <0.1 & 10.74 \\ \mathrm{Fe} & 0.0(<1 \%) & <0.1 & 5.92 \\ \mathrm{Mn} & 4.12(103 \%) & 3.99 & 17.21 \\ \mathrm{Mg} & 8.7(98 \%) & 8.82 & \end{array}$

a Values are reported in $\mathrm{mg}$ of metal found in the solution after precipitation from $20 \mathrm{~mL}$ of Berkeley Pit water. Values in parenthesis are the percent of metal remaining in solution based on original Berkeley Pit water.

$\mathrm{b}$ Metal content in permeate after $\mathrm{pH}$ adjustment to 5.6 and ultrafiltered.

c Values are the amount in $\mathrm{mg}$ of each metal in $20 \mathrm{ml}$ of Berkeley Pit water.

$\mathrm{d}$ After a water wash of the precipitate, an additional $10 \%$ of copper was collected.

To show PF effectiveness in meeting metal-ion discharge levels after the precipitation of iron and aluminum, the Berkeley Pit water $(20 \mathrm{~mL})$ was treated in a similar manner as above resulting in a final $\mathrm{pH}$ of 5.6. The supernatant was removed from the iron/aluminum precipitate and ultrafiltered through a 10,000 molecular weight cutoff membrane. Analysis of the permeate discharge waters by ICP-AES indicated metal concentrations below detectable limits for copper, aluminum, iron, and zinc of $<0.1 \mathrm{ppm}$ and nickel, chromium, lead, and cadmium of $<0.3 \mathrm{ppm}$.

In summary, the preliminary evaluation of polymer filtration as a technology for the recovery of metal ions from the Berkeley Pit has proven to be very encouraging. We have successfully shown that the addition of the appropriate amount of water-soluble polymer to the untreated water results in selective precipitation of the iron and aluminum from the copper, zinc, and manganese by a selective and kinetically rapid process. This has the potential advantage of an in-line treatment process as opposed to a batch type process. It has been shown in previous work that the zinc and copper can be separated selectively by $\mathrm{pH}$ adjustment. The polymers are recycled in the system for additional metal ion recovery, therefore, a secondary waste stream is never generated. Analysis of discharge or permeate waters were below detectable levels of metals which demonstrates the effectiveness of PF as a polishing step for low-level concentrations of metals. 


\subsection{Arsenic from Drinking Water}

Background: The group V-A and VI-A elements exist in the environment often as oxyanions. Some of the more toxic of these elements include arsenic, selenium, and antimony. They enter the environment from a variety of both agricultural and industrial activities. For example, the Kestersen reservoir has been the recipient of channeled agricultural runoff in California, which has natural selenium in the soils making the reservoir hazardous to wildlife and other uses. Arsenic is used in agricultural pesticides, in chemical weapons, and as hardeners in copper/lead alloys. Antimony is used in hardening of metals such as in some bullets, bearings; and in storage batteries. All these metals are emitted during smelting operations. In the heavily industrialized Eastern block countries, there is a problem of arsenic contaminated drinking water. The drinking water standards for As in the US is less than 0.1 ppm.

Experimental: We received several gallons of drinking water samples from Hungary. We analyzed the water for a series of metals (copper, nickel, aluminum, iron, chromium, zinc, lead, cadmium) using ICP-AES and found them below detection level ( $<0.01 \mathrm{ppm})$. The samples were analyzed for arsenic and found to contain $0.11 \mathrm{ppm}$ (Galbraith Lab.) which is at or slightly above US drinking water standards. A new, first generation water-soluble polymer called Metal-Set Q developed at LANL was tested on the Hungarian waters to remove arsenic. The results are shown in Table 2 below.

Table 2. The Treatment of Hungarian Drinking Water to Remove Arsenic.

Sample

As received water Ultrafiltered water (no polymer) Metal-Set-Q (0.1 wt/vol.\%)
Arsenic (ppm)

$0.11(0.10)$

$0.11(0.10)$

$0.02(0.02)$

It can be seen that simple ultrafiltration through a 10,000 molecular weight cutoff membrane (Centricon 10, Amicon) does not remove any of the arsenic. When a small amount of polymer was added to the solution to give $0.1 \mathrm{wt} / \mathrm{vol} \%$ solution, approximately $60 \%$ of the arsenic was removed from the $\mathrm{pH} 7.95$ water. Since this is drinking water, considerable adjustment chemistry is undesirable. The fact that we could remove a large portion of the arsenic and readily meet drinking water standards is an important step forward.

In the program development arena, it is anticipated that the technology will be commercialized by our industrial partner, Micro-Set, who will be making the polymers and ultrafiltration units commercially available along with supplying a service to the appropriate industry. This has opened the field of drinking water treatment as a need both in the US and abroad. It has allowed us to have a success, even if it is only a first generation polymer, in the 
removal of oxyanions from simple water systems. The next step is more complicated waste waters that have competing anions such as sulfate. In anticipation that the standards will be lowered even further, we plan to develop polymers that are both reversible and can reach even a lower level of arsenic removal. Studies on selenium and antimony are anticipated.

\subsection{Recovery/Removal of Mercury from Solids}

Background: There are many solids from which the recovery or removal of mercury would be desirable. There are cases where there has been soil contamination from mercury spills and natural gas lines, equipment contamination from the use of mercury in industrial processes, and contamination of DOE facilities. Major feed stocks for mercury recyclers include batteries, thermometers, switches, thermocouples, chloralkali wastes, and residues from remediation activities.

One such DOE facility is Y-12 at Oak Ridge, TN, the lithium processing facility. It is estimated that there is 7000 pounds of mercury in the system. The plant is now scheduled for decommissioning in FY 1998. The problem is that there are pipes and recesses that are not easily accessible for physical cleaning and the whole plant is not amenable to the retorting process commonly used to recovery mercury from other solids. New, cost effective approaches to decontamination of mercury from solid surfaces are needed.

Another example where mercury recovery is desirable is from electrical fixtures. Small amounts of mercury metal is used in fluorescence light tubes. When the lifetime of the light tube is completed the disposal of the material in landfills has become an environmental hazard because of the large numbers of light tubes in use. Though the amount of mercury in the light tubes has been decreasing over the years there is still a considerable amount of mercury potentially released into the environment. The most common current technique for recovering the mercury is through retorting, which is heating the material above the vapor pressure of mercury and recovering the mercury vapors in a condenser system. Though this is a very selective mode of recovering mercury, as no other metal has as low a vapor pressure as mercury, this is an energy intensive approach.

The physical and chemical properties of mercury metal make it particularly difficult to simply remove by flushing in aqueous or organic solvents. Mercury metal has minimal solubility in water and organic solvents. Because it is a heavy liquid under normal conditions, it easily flows into cervices in equipment and readily coats and contaminates surfaces. Mercury reacts with some aromatic organic compounds to form highly toxic organomercury compounds that have high vapor pressures and easily get into the environment. Past approaches to mercury removal besides retorting have included the use of oxidizing acids and leaching detergents or reagents, some solvent extraction and some ion exchange. 
Water-soluble metal-binding polymers have been shown to be good ligands to remove toxic metals, such as lead and chromium, from surfaces of solids such as soil. Once the polymer solution is physically separated from the soil by settling or macrofiltration, the watersoluble metal-bound polymer can be concentrated using ultrafiltration. The metal can be released from the polymer concentrate and recovered. The metal-free polymer can then be recycled for further solids leaching. This polymer filtration process reduces the secondary waste that is produced during decontamination or soil leaching processes. This process has been demonstrated at the bench scale on CalWest Superfund soils and was found to leach lead to below required levels. This same technology has potential for the removal/recovery of mercury from a variety of solid materials and surfaces.

Since this process recovers metal ions, not free metal, it is necessary to put the mercury into solution in a stable oxidation state (perform a mild oxidation). Nitric acid oxidation to $\mathrm{Hg}^{2+}$ is a possibility. Often a surface oxide coating is formed on the liquid mercury that prevents further or complete oxidation of the mercury. Thus, dispersion of the mercury into very small droplets with large surface areas is necessary for complete oxidation and solubilization of the mercury to occur. In some cases, dispersion of the mercury is not easily attained. Nitric acid leaching is quite harsh conditions, rough on pipes, often solubilizing soils or other solids present in the system and is not very selective. Secondly, it can lead to large amount of secondary mercury-containing, nitrate wastes.

Experimental: We have performed some preliminary experiments to determine some appropriate preliminary conditions to solubilize mercury using water-soluble metal-binding polymers. Further optimization and testing should allow us to adapt this technology to a variety of applications for recovery and removal of mercury from a variety of solid materials. Outlined below are some of the conditions tested for mercury solubilization.

Test 1: Elemental $\mathrm{Hg}$ was obtained with which to run experiments that could be monitored for the disappearance of $\mathrm{Hg}$ by sight. Five different molarities of nitric acid were used. It was observed that oxidation and solubilization could be accomplished in the 16 to 2 molar range of nitric acid with vigorous mixing in 5 to 60 minutes. One molar nitric acid could not oxidize the mercury metal completely even after several days.

Test 2: Because even 1 molar nitric acid is quite strong and could cause nonspecific dissolution of the solids being leached for mercury removal, even more mild conditions were pursued.

a. The reaction from above where 1 molar nitric acid was used was repeated such that there was excess $\mathrm{HNO}_{3}$ relative to $\mathrm{Hg}$. A chelating polymer was also added to enhance solubility. $0.03 \mathrm{gm}$ of $\mathrm{Hg}(0.149 \mathrm{mmol})$ was used with $1 \mathrm{~mL}$ of $1 \mathrm{M} \mathrm{HNO} 3(1.0 \mathrm{mmol})$ and 1 
$\mathrm{mL}$ of $50,000 \mathrm{ppm}$ Metal-Set $\mathrm{Z}$ polymer. The $\mathrm{Hg}$ all went into solution leaving no gray particulates after about a hour of sonication plus sitting overnight.

b. To $0.030 \mathrm{gm}$ of $\mathrm{Hg}$ was added $5 \mathrm{~mL}$ of $50,000 \mathrm{ppm}$ Metal-Set-Z polymer, (.i.e., 120 $\mathrm{mg}$ needed on a mercury binding capacity basis and $250 \mathrm{mg}$ was added). The $\mathrm{pH}$ of the mixture was basic and the mixture was sonicated while air was bubbled through the solution. After about 30 minutes the elemental $\mathrm{Hg}$ appeared to be gone, but there was a gray precipitate observed. After overnight shaking the solution looked some clearer, but there was still gray precipitate.

From these initial experiments it is clear that we are on the verge of finding mild conditions that can be used to leach solid surfaces and materials of mercury contamination.

\subsection{Metal Recovery from Mining Ores}

Background: Open pit mining and hardrock tunnel mining has raised the environmental issue of the use of our public lands and the conditions in which they should be given back to the public. If advanced mining technology could be developed where open pits or tunnels were not necessary to extract the metal of interest it would be a great advantage. Injection mining is where small-bore holes are drilled and reagents are injected into the holes. The metal-loader reagent is recovered from another nearby hole. Selective reagents that can easily accomplish this task that are environmental safe and technically effective are needed.

Experimental: The use of water-soluble chelating polymers in the recovery of metals from ore deposits in leach piles or by injection well mining was tested. The water-soluble polymer Metal-Set- $Z$ was tested for the removal of copper from a copper ore deposit in what is believed to be a quartz rock obtained from the Copper Queen mine in Bisbee, Arizona. A 100 $\mathrm{mL}$ solution of polymer ( $4 \%$ by weight) was contacted with the rock $(20.7 \mathrm{~g}$ ) containing copper deposits. Agitation was provided by magnetic stirring for a 24 hour period at which time the polymer solution was decanted and fresh polymer $(100 \mathrm{~mL}, 4 \%$ by weight) added. After an additional 48 hours the two solutions were combined and analyzed for copper resulting in a concentration of $203 \mathrm{ppm}$. The total amount of copper extracted from the rock was $71 \mathrm{mg}$ or about $0.4 \%$ by weight. As a measure of the efficiency of copper removal from the first two solutions, the rock was subsequently crushed and leached for additional copper using Metal-Set-Z (100 mL, $4 \%$ by weight) solution. Analysis of this second solution, after 24 hours of contact, yielded only an additional $8.6 \mathrm{mg}$ of copper. Total copper removed was $78.6 \mathrm{mg}$. Analysis of the solutions for iron gave $0.9 \mathrm{mg}$ of iron leached from the combined first two solutions and $0.6 \mathrm{mg}$ in the second solution. A portion of the pre-leached, crushed rock $(4.79 \mathrm{~g})$ was treated with concentrated nitric acid. The solution was analyzed for copper resulting in a total of $1.51 \mathrm{mg}$ or approximately $0.03 \%$ by weight. Assuming the material was 
representative of the original rock the conclusion is that more than $90 \%$ of the copper present in the original rock was leached from the solid by stirring in the presence of polymer solution. Based on the above results, the polymer shows the ability to extract copper from ore not only in a selective manner, but was also able to effectively extract a significant percentage of the copper from the rock without the need for crushing.

\subsection{Copper Removal from Catalyst}

Background: The recovery of precious metals from catalytic materials both from spent auto catalysts, recovery of copper from catalysts used for $\mathrm{NO}_{\mathrm{x}}$ abatement, and heterogeneous catalyst has a large market potential. Certain metals such as the precious metals are particularly valuable. With pending reductions in allowable $\mathrm{NO}_{\mathrm{x}}$ emissions from automobiles, intense research into new catalysts is underway. Copper-loaded zeolites (Cu-ZSM-5) are currently the most effective catalysts to address this problem.

Experimental: We have been evaluating the recovery of such valuable metals from catalysts. A solution of a water-soluble polymer was used to leach metal ion from a catalyst. Zeolytic catalyst $(0.2 \mathrm{~g}, \mathrm{ZSM}-5)$ obtained from Englehart loaded with copper $(0.28 \mathrm{wt} . \%)$ was stirred with $10 \mathrm{~mL}$ of a $0.5 \mathrm{wt} . / \mathrm{vol}$.\% solution of Metal-Set-Z for a period of 24 hours at room temperature. Following a single pass or contact period, greater than $83 \%$ of the copper was found to have moved or extracted from the catalyst as determined by ICP-AES.

\subsection{Removal of Plutonium and Americium from TA-50 Wastewaters}

Background: At Los Alamos, the largest low level mixed waste generated is the sludge from the TA-50 waste water treatment facility. Presently, the acid and caustic waste streams produced at LANL are neutralized in this facility using an iron-lime precipitation process. The problems associated with this process are 1) the removal of the actinides with this precipitation technique generates a huge volume of waste (currently stored as a low level mixed waste) and 2) Los Alamos is facing new, low actinide discharge limits that are not attainable with the existing precipitation process. The consequences of these two problems are immense. Storage of the large quantities of low-level mixed wastes is expensive and requires constant monitoring. If at some point LANL is allowed to dispose of this waste at the TA-54 low level waste landfill, these wastes will use a tremendous amount of limited landfill space. Permitting of a new landfill would be quite expensive and could potentially be denied by the state. It is imperative that LANL make the best use possible of such a resource. The best possible solution to both these problems is to demonstrate a new method for removal of the actinides and toxic metals from these waste waters without generating a large secondary waste stream. 
Experimental: Initial experiments have focused on the reduction of total alpha count in TA-50's influent by Polymer Filtration technology. Efforts have been concentrated on the optimization of conditions on a bench scale using the water-soluble polymer Metal-Set $\mathrm{P}$, which has shown to have selectivity for Pu and Am. Samples of the influent to be treated were 24 hour composites and, as expected, varied significantly in both $\mathrm{pH}$ and in total alpha activity. It was therefore necessary to make adjustments to evaluate the polymer's performance at different $\mathrm{pH}$ values. The polymer dosage study of Metal-Set $\mathrm{P}$ for total alpha removal was performed at $\mathrm{pH} 7.5$. The influent was first treated by filtering through a Betz $1175(10 \mathrm{ppm}$ dose) pre-coated 0.45 micron filter. As shown in the table a significant amount of activity was removed $(97.7 \%$ ) by simple ultra-filtration in the absence of the polymer. This was not surprising as earlier studies had obtained similar results. This suggest that a large amount of the activity is in a colloidal or suspended solid form. The addition of $10 \mathrm{ppm}$ of Metal-Set $P$ further reduced the activity (99.2\%). A two orders of magnitude increase in polymer dosage $(1000 \mathrm{ppm})$ removed the level to $99.6 \%$.

Table 3. Effects of Polymer Dosage on Gross Alpha Removal from Influent

$\begin{array}{cccc} & \begin{array}{c}\text { Turbidity } \\ (\mathrm{NTU})\end{array} & \begin{array}{c}\text { Gross Alpha } \\ (\mathrm{pC} \mathrm{i} / \mathrm{L})\end{array} & \text { \% Removal } \\ \text { Influent } & 43.8 & 19,416 & \\ \text { Filtrate } & 0.068 & 858 & 95.6 \\ \begin{array}{c}\text { Permeate } \\ \text { (no polymer) }\end{array} & 0.299 & 455 & 97.7 \\ \begin{array}{c}\text { Permeate } \\ (10 \mathrm{ppm} \text { polymer) }\end{array} & 0.107 & 164 & 99.2 \\ \begin{array}{c}\text { Permeate } \\ (1000 \text { ppm polymer) }\end{array} & 0.123 & 80 & 99.6\end{array}$

Further studies set the polymer dosage at $100 \mathrm{ppm}$ independent of the total alpha count in the influent. Results of the $\mathrm{pH}$ optimization have shown that the polymer consistently performs best in the range of 4.0-5.0. The table below gives results of total alpha removal at two different $\mathrm{pH}$ values with and without the Betz 1175 pre-coated filtration. In these experiments the total alpha of the influent was high at $63,707 \mathrm{pCi} / \mathrm{L}$. 
Table 4. Optimization of the Polymer Filtration Process.

\begin{tabular}{|c|c|c|c|c|c|}
\hline \multicolumn{3}{|c|}{$\begin{array}{l}\text { Pre-Coat } \\
\text { Filtration }\end{array}$} & \multicolumn{3}{|c|}{$\begin{array}{l}\text { Ultra- } \\
\text { Filtration }\end{array}$} \\
\hline Sample & $\mathrm{pH}$ & $\begin{array}{c}\text { Turbidity } \\
\text { (NTU) }\end{array}$ & $\begin{array}{l}\text { Gross Alpha } \\
(\mathrm{pCi} / \mathrm{L})\end{array}$ & $\underset{(\mathrm{pCi} / \mathrm{L})}{\mathrm{pH}}$ & Gross Alpha \\
\hline $\begin{array}{l}100 \mathrm{ppm} \\
\text { polymer }\end{array}$ & & & & 4.5 & 275 \\
\hline $\begin{array}{c}10 \mathrm{ppm} 1175 \\
100 \mathrm{ppm} \\
\text { polymer }\end{array}$ & 4.5 & 0.038 & 21,403 & 4.5 & 84 \\
\hline $\begin{array}{c}10 \mathrm{ppm} 1175 \\
100 \mathrm{ppm} \\
\text { polymer }\end{array}$ & 7.4 & 0.145 & 8630 & 7.4 & 1077 \\
\hline $\begin{array}{c}10 \mathrm{ppm} 1175 \\
100 \mathrm{ppm} \\
\text { polymer }\end{array}$ & 7.4 & 0.145 & 8630 & 4.1 & 287 \\
\hline
\end{tabular}

The above data illustrates the importance of the $\mathrm{pH}$ during treatment for both the Polymer Filtration and the pre-coat filtration stages for optimum alpha removal. The best results were obtained when the influent was treated with the Betz 1175 pre-coat and the Polymer Filtration at a $\mathrm{pH}$ of 4.5 were $99.9 \%$ of the activity was removed. Previous studies have confirmed that the Metal-Set $\mathrm{P}$ polymer binds most effectively to $\mathrm{Pu}$ in the $\mathrm{pH}$ range of 4.0-5.0.

Efforts are currently under way to identify the speciation of the alpha activity that ends up in the permeate. Early indications are that the majority of counts are coming from Pu-238 and Pu-239 with a small amount of Am-241. There is small additional count from an unidentified source. It is suspected that these counts could be from metals complexed with chelators such as EDTA, which are commonly found in cleaners. We are looking into the use of peroxides, ozone or UV as a method for destroying these competing chelators prior to using the polymer filtration treatment process. 